\title{
Musikindustrin i Zimbabwe
}

Massmediernas betydelse för vårt sekels musik är ett faktum, liksom också det att radion spelar en stor roll i utvecklingsländernas kommunikationsfält. Trots detta har de moderna medierna och musiken $\mathrm{i}$ tredje världen förblivit ett så gott som obeaktat ämne både bland etnomusikologer och kommunikationslärda.

Den blygsamma forskningen är överraskande med tanke på hur viktiga frågor traditionalismen och modernismen samt nationalismen och internationalismen är för de unga staterna. De äldre musikformernas omvandling till populärmusik och den moderna teknologins inverkan på musikens utveckling är ju inte längre några nyheter.

Denna artikel baserar sig på kapitlet Musikindustrin i Zimbabwe, som ingår i min pro gradu -avhandling (se Brusila 1992). Arbetet föregicks av två forskningresor till Zimbabwe år 1991 och utfördes i samband med projektet Mediafrica.

I artikeln presenterar jag den omgivning som musikmedierna verkar i och själva musikindustrins utformning. Jag önskar kunna belysa de faktorer som inverkar på musikproduktionen och spridningen av musiken i ett afrikanskt land. Slutligen beskriver jag i korta drag de följder som industrins uppbyggnad har för musikutbudet. 


\section{Från vinyl till kassett}

Den zimbabwiska musikindustrins utveckling följer långt samma mönster som de övriga industrigrenarnas. De europeiska invandrarna skapade en nationell rundradioverksamhet, som hade drag av motsvarande europeiska system. Skivindustrin skapades av sydafrikanska bolag som grundade filialer i landet.

År 1965 bröt det dåtida Rhodesia med Storbritannien och förklarade sig självständigt. Denna "UDI", Unilateral Declaration of Independence, ledde till att Förenta Nationerna utlyste det minoritetsstyrda landet i handelsbojkott. Sanktionerna tvingade alla Rhodesias industrigrenar, däribland också musikindustrin, att anpassa sig till en högre grad av självförsörjning.

Den svarta befolkningens maktövertag år 1980 och den påföljande självständigheten har i praktiken inneburit få ändringar i ägoförhållanden och verksamhetsformer. Den största formella skillnaden är det nationella rundradiobolagets nya svarta styre. För skivindustrin har UDI-periodens arv inneburit ett besvärligt hinder för utveckling och expansion. Den föråldrade tekniska utrustningen och den strama valutakontrollen har bidragit till att hålla läget oförändrat.

I Zimbabwe hann vinylskivan befästa sin position under UDI-perioden, vilket effektivt beskyddade landet från olaglig piratkopiering. Då den strikta statliga kontrollen fortsatte under självständigheten importerades det inte heller några kassettspelare till Zimbabwe. I slutet av 1980-talet blev det dock allt svårare att få reservdelar till de gamla skivspelarna. I stället har konsumenterna under de senaste åren själv hämtat bandspelare och kassetter från Sydafrika och Botswana.

Konsumenternas nya intresse för kassetter försätter industrin i en mycket svår situation. Skyddet mot piratismen kan försvinna, vilket utgör ett hot för hela den professionella fonogramproduktionen. Samtidigt försvåras också underhållet av den gamla skivframställningen.

Ett annat exempel på svårigheterna under självständigheten är de statliga tjänstemännens sätt att klassificerar musikutrustning som lyxartiklar. Det här innebär att det är mycket svårt att importera instrument och förstärkaranläggningar. Till och med musiker som återvänder från utlandsturnéer kan ha svårt att ta hem sin nyinförskaffade utrustning. I dag finns det inte en enda instrumentaffär i Zimbabwe.

Musikbranschen har under de senaste åren arbetat mycket för att höja sitt anseende som en seriös industri. Som ett led i utvecklingen 
grundades i augusti 1990 Zimbabwe Music Industry AssociationZIMIA (se ZIMIA - The Forming of a Music Industry Association in Zimbabwe, 1992). Föreningens uppgift har främst varit att fungera som takorganisation och diskussionsforum för industrins olika delområden. En stor del av verksamheten har gått ut på att skapa förståelse för branschens problem bland de statliga tjänstemän, som till exempel bestämmer om valutakontroll, importrättigheter osv.

\section{Industrins grundstruktur}

Följande schematiska framställning av musikindustrin i Zimbabwe (diagram 1) baserar sig huvudsakligen på en kombination av två vedertagna musikindustriella modeller.

Industrins olika produktionsfaser har beskrivits utgående från den modell som Roger Wallis och Krister Malm använder i sitt grundläggande verk Big Sounds From Small Peoples (1984, 50-57). Wallis och Malm koncentrerar sig på den nationella industrin i små länder, men samtidigt påpekar författarna att de olika faserna kan ägas och kontrolleras av ett eller flera utländska företag.

Den andra utgångspunkten är Paul Hirsch teori (Hirsch 1969, 47) om skivindustrins grindvakters funktioner. Enligt Hirsch är det kännetecknande för kulturindustrier, däribland också musikbranschen, att det är ytterst svårt att förutspå produkternas framgång. Därför producerar bolagen en stor del varor, av vilka endast en del slutligen når konsumenterna. Industrins olika stadier mellan konstnären och konsumenten utför således en s.k. förurvalsprocess, då en stor del av produkterna steg för steg faller bort. Skivbolagen och radion är centrala grindvakter $\mathrm{i}$ filtreringen.

I diagrammet över den zimbabwiska musikindustrin har skivindustrins produktionsfaser förenats med massmediernas grindvaktsfunktioner, för att på detta sätt göra alla filtreringsprocesser synliga.

Schemat koncentrerar sig på musikindustrin, inte musikkulturen i sin helhet. Figuren kan med andra ord sägas ge en missvisande bild av musiklivets allmänna karaktär eftersom den inte beskriver amatörmusicerande, fackliga och statliga organisationer, eller till exempel den zimbabwiska musikens exportstrukturer. Huvudsyftet med figuren har dock varit att på ett överskådligt sätt beskriva de element 


\section{Brusila}

Diagram 1. Den zimbabwiska musikindustrins grundstruktur

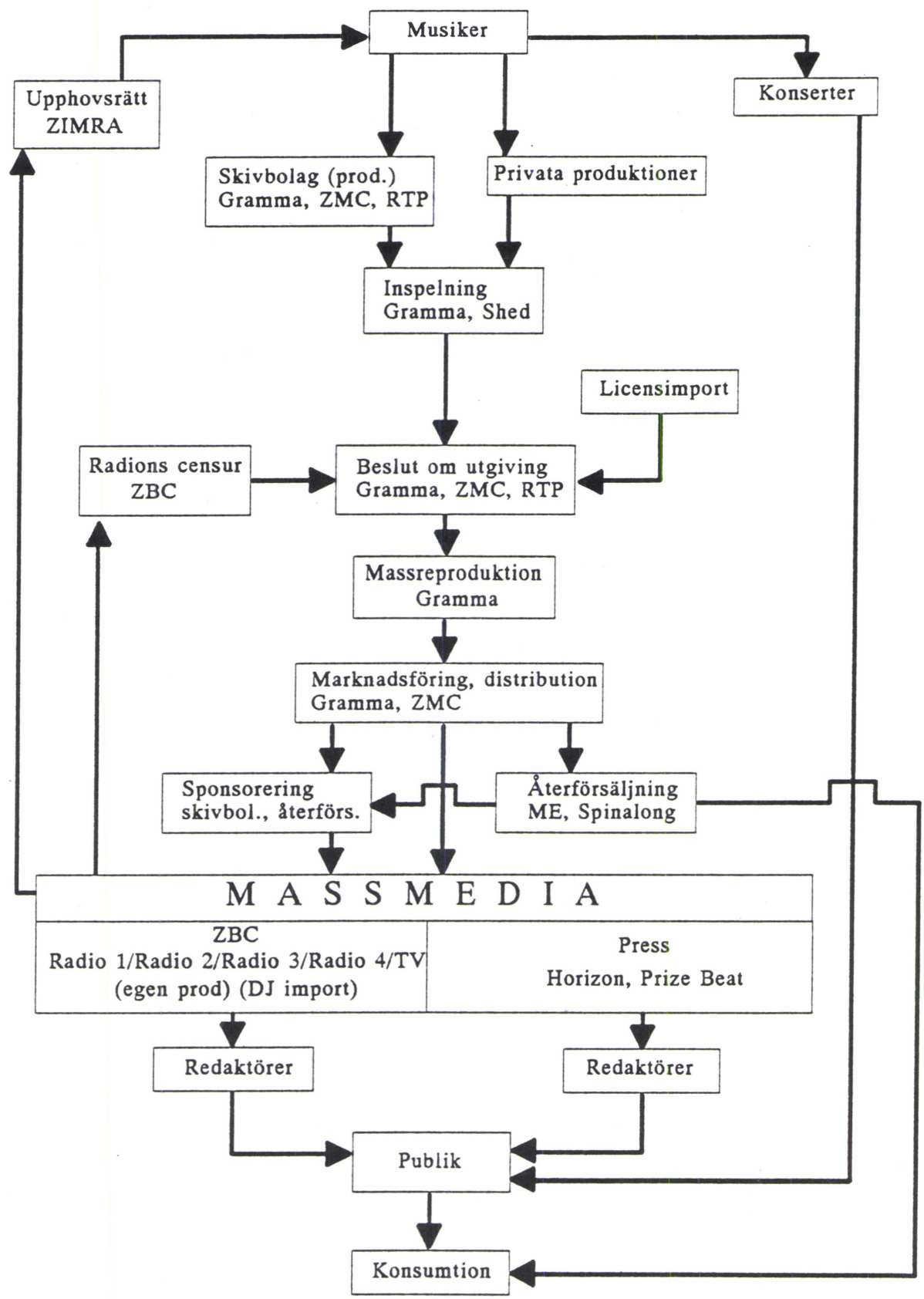


som påverkar industrin och de interna förhållandena inom branschen därför har bland annat ovannämnda aspekter ute-lämnats.

Fokuseringen på industrins filtreringsprocesser innebär också oundvikligt att såväl "musikkedjans" första länk, d.v.s. själva musicerandet, som den sista länken, nämligen musikkonsumtionen, faller $i$ skymundan.

Skivindustrin är naturligtvis endast en del av musiklivet i Zimbabwe och på grund av de ekonomiska realiteterna kan skivkonsumtionen aldrig bli särdeles stor. Ungefär hälften av Zimbabwes befolkning är under femton år och minimilönen i landet är 158 Zimbabwe Dollar (Sandberg - Edenborg 1990: 14). Det här innebär att förhållandevis få människor har råd att köpa LP-skivor som kostar kring 30,00 ZD.

För de flesta zimbabwiska musikerna utgör skivindustrin antagligen inte heller någon huvudinkomstkälla. Utan närmare forskning är det svårt att ge några noggranna uppgifter, men man kan anta att skivförsäljningens ringa storlek och de små royaltyersättningarna tvingar flera musiker att skaffa sina inkomster från turnéer och till och med helt andra yrkesförvärv.

Trots att Zimbabwes musikindustri i internationell jämförelse inte är stor så kan man tala om en mycket livfull verksamhet som utan tvekan utgör en central del av landets musikliv. Med radions hjälp når skivorna dessutom en mycket stor skara passiva konsumenter.

Till exempel konserternas viktiga roll för musikerna minskar nödvändigtvis inte radions och skivindustrins grindvaktsfunktioner. Det är nämligen fortfarande svårt för en stor del av befolkningen att gå på konserter. De flesta tillställningarna arrangeras i tätorter och biljettpriserna är förhållandevis höga (15-30 ZD), vilket gör det omöjligt för landsbygdens befolkning att se orkestrarna uppträda. Flera kvinnor och äldre människor kan också uppleva det svårt att besöka danskrogar och klubbar på grund av utskänkningsställenas tvivelaktiga rykte.

\section{Skivbolag}

År 1959 grundade det sydafrikanska skivbolaget Gallo Records ett dotterbolag i Zimbabwe och kort därefter gjorde konkurrenten Teal det samma (Hagelthorne 1991). Företagens beslut om att utvidga sin verksamhet kan ses som en följd av de sydafrikanska musikernas 
stora popularitet i det norra grannlandet. Till en början var utbudet konservativt och försiktigt, men då den svarta befolkningen på 1970talet fick råd att köpa skivspelare märkte bolagen vilken åtgång den lokala populärmusiken hade och ändrade produktionen därefter. (Zindi 1985, 5-6)

Teal inkorporerades senare, som en följd av flera bolagsuppköp, i det brittiska bolaget Lonrho. Skivbolaget övergick också till att använda namnet Gramma Records för att ta avstånd från det sydafrikanska Teal. Lonrho, som ursprungligen hette London Rhodesia Mining Company, är ett konglomerat med stark representation i Zimbabwe, där den har en betydande ställning i landets gruvindustri och agrikulturella produktion. Gramma har 96 anställda (studio och skivfabrik medräknade), och bolaget utgör endast en minimal gren av hela Lonrho, som allt som allt anställer 25.000 människor. (Howard 1991)

Den sydafrikanska mediajätten Gallo valde att behålla sin zimbabwiska filial också efter att landet hade blivit självständigt. Bolagets namn ändrades till Zimbabwe Music Corporation (ZMC) och officiellt såldes det åt det holländska företaget Blue Chip Music BV, som dock ägs av Gallo. I praktiken har Zimbabwe Music Corporation hela tiden styrts av den zimbabwiska ledningen, som har gjort självständiga beslut om utgåvor, licenskontrakt osv. Zimbabwe Music Corporation anställer 45 personer. (Hagelthorne 1991)

Flera transnationella bolag har planerat att grunda filialer i Zimbabwe, men inget av dem har påbörjat någon egentlig verksamhet $\mathrm{i}$ landet. I stället har de utländska bolagen slutit licenskontrakt med Gramma och Zimbabwe Music Corporation. Importen är möjlig eftersom Zimbabwe, i skillnad till de flesta andra afrikanska länder, har så lite piratism. Verksamheten är också profitabel för de internationella licensägarna eftersom regeringen har bibehålligt industrins tillstånd att betala licensarvoden i utländsk valuta. (Howard 1991)

De utländska bolagen förser sina handelspartners med färdiga matriser, konvolutoriginal och PR-material - varor som i dagens läge är ytterst dyra i Zimbabwe. Allt nödvändigt förmedlas av de transnationella bolagens filialer och representanter i Sydafrika. På det här sättet blir det i själva verket avsevärt billigare att licensera en utländsk skiva än att producera egna artister. (Hagelthorne 1991)

Gramma och Zimbabwe Music Corporation kan kallas för majors i Zimbabwe. Bolagen producerar egna artister, men med hjälp av 
licenskontrakt ger de också ut internationell musik. De har också investerat i industrins olika delområden, ss. studioverksamhet, massreproduktion och distribution.

Vid sidan av dessa majors verkar det numera också ett oberoende bolag, Record and Tape Promotions (RTP), som har ett försäljnings- och distributionskontrakt med Gramma. Record and Tape Promotions grundades år 1988 av verkställande direktör Mike Ralph som föregående år hade lämnat sin tjänst vid Zimbabwe Music Corporation. Också RTP har försökt få tillstånd att importera skivor, men tillsvidare har de fått avslag på sina ansökningar. Bolaget ägs av Ralph och hans bror och det anställer fyra människor. (Ralph 1991)

Record and Tape Promotions är det enda oberoende skivbolaget $i$ Zimbabwe, men i vissa fall har framgångsrika musiker själv finansierat inspelningen av sina skivor, varefter de har sålt skivans masterband åt någotdera stora bolaget. Denna verksamhet har dock förblivit blygsam som en följd av skivbolagens ytterst monopolistiska verksamhetspolitik.

\section{Musikinspelning}

De första egentliga musikstudiorna grundades i Zimbabwe i början av 1970-talet. Det var fråga om en fyraspårs- och två åttaspårsstudior, som användes av Teal och Gallo för inspelning av skivor. Flera av studiornas aktieägare valde att emigrera efter att Zimbabwe blev självständigt och samtidigt exporterades en del av utrustningen. (Roskilly 1992, 9-10)

På 1980-talet har inspelningstekniken långsamt förnyats och utvecklats. För tillfället fungerar tre studior som erbjuder möjligheter till skivinspelning. Skivbolaget Gramma äger en studio med 16-spårs och en med 24-spårsutrustning. Det enda oberoende inspelningsbolaget, Shed Studios, har en 16-spårsutrustning, men studion planerar att utvidga med ytterligare en 24-spårs enhet. Det finns också flera mindre studior som används i första hand till radioreklamer och demonstrationsbandningar. (Roskilly 1991)

Trots den långsamma positiva utvecklingen försvåras verksamheten av reparationsproblem och brist på utrustning. Valutarestriktionerna och den stränga statliga kontrollen har gjort det mycket svårt att importera ens den nödvändigaste elektroniska apparaturen. Som exempel kan nämnas att Shed Studios år 1989 fick tillstånd att im- 
portera två tvåtums bandspolar - denna mängd räcker till för inspelning av en timme musik. (Roskilly 1992,11)

\section{Massreproduktion}

Den dyra skivpressningen har närapå fått en dominerande roll i hela industrins produktionskedja. Tidigare hade både Zimbabwe Music Corporation och Gramma var sin skivfabrik som de hade införskaffat billigt under den rhodesiska tiden. Utrustningen i båda fabrikerna var föråldrad redan på 1970-talet, men på grund av handelsblockaden var det omöjligt att förnya den. Problemen har fortsatt under självständigheten som en följd av den stränga importkontrollen. (Hagelthorne 1991)

Skivpressningens problem med höjda driftskostnader och en allt sämre åtgång av vinylskivor ledde i slutet av 1980-talet till att Gramma köpte Zimbabwe Music Corporations fabrik. Transaktionen kan ses som ett ekonomiskt tvång eftersom de båda faciliteterna $i$ själva verket hade utnyttjats endast till 20-30 \% av sin fulla kapacitet. Samtidigt har köpet dock gett Gramma en stark ställning i branschen, framför allt eftersom Gramma också kopierar alla kassetter i Zimbabwe. (ibid.)

Grammas utrustning kan sägas vara hopplöst föråldrad $i$ jämförelse med de industrialiserade ländernas direktgraverande anläggningar. Priset på importvarorna PVC och matrislack har stigit och det är allt svårare att få tag på råvarorna då vinylskivan börjat försvinna från världsmarknaden. Den industrialiserade världens konsumenter håller på att gå över till compactskivor och tredje världens musikindustrier består så gott som uteslutande av kassettmarknader. (Howard 1992, 34)

I Zimbabwe är compactskivan knappast något realistiskt framtida alternativ på grund av de dyra framställningskostnaderna och marknadens ringa storlek. Kassetterna däremot har visat sig bli allt populärare. Gramma sålde till exempel år 1985 grovt räknat tre skivor per en kassett, men redan 1990 utgjorde kassetterna över $60 \%$ av försäljningen. Samtidigt stagnerade skivornas åtgång så gott som helt. (Howard 1992, 38) 


\section{Återförsäljning}

De skivor och kassetter som ges ut i Zimbabwe distribueras nationellt av Gramma och Zimbabwe Music Corporation. Själva återförsäljningen sköts dels av mindre lokala föratagare, dels av stora nationella kedjor.

Den första större skivaffären Spinalong grundades redan 1968 som ett familjeföretag och bolaget expanderade snabbt till en hel butikskedja. I början av 1980-talet övergick Spinalong i Zimbabwe Music Corporations ägo, men i slutet av årtiondet såldes bolaget igen åt en privat företagare. Skivbolaget hade nämligen kritiserats skarpt för att favorisera sina egna skivaffärer, bland annat när det gällde varuleveranser, vilket försämrade förhållandena till de övriga, fristående återförsäljarna. Som en följd av kritiken beslöt Zimbabwe Music Corporation att år 1989 sälja Spinalong åt Bill Annandale, som också blev affärskedjans verkställande direktör. (Annandale 1991)

Spinalong har 17 skivaffärer i Zimbabwe. Största delen är placerade i städerna med anknytning till något stort varuhus. En märkbar del av skivorna som säljs i kedjans butiker är internationella artisters produkter som de zimbabwiska skivbolagen gett ut. Enligt VD Annandale finns det bland städernas förmögna konsumenter en stor efterfrågan på compactskivor och Spinalong har ansökt om valutarättigheter för att importera compactskivor till försäljning. Tillsvidare har importen dock endast skett informellt i små mängder utan statligt tillstånd. (ibid.)

Den största återförsäljaren Music Express grundades 1985 av bolagets ägare David Smith. Music Express hade från första början som mål att erbjuda samma skivutbud åt alla konsumenter i hela Zimbabwe och kedjan har lagt speciell omsorg $i$ att betjäna den svarta befolkningen i småstäderna och på landsbygden. År 1990 hade Music Express 52 skivaffärer. De flesta affärerna verkar i samband med större butiker. (Smith 1991)

Förutom de större kedjorna finns det några större, lokala affärer $\mathrm{i}$ Harare och Bulawayo. En stor del av skivorna säljs fortfarande av enskilda småföretagare i så kallade "record bars". 


\section{Det nationella rundradiobolaget och pressen}

Det nationella rundradiobolaget Zimbabwe Broadcasting Corporation (ZBC) skapades i början av självständigheten då Rhodesian Broadcasting Corporation slogs samman med de svarta frihetskämparnas radio Voice of Zimbabwe. Den rhodesiska radions historia sträcker sig ända till 1930-talet då de första provsändningarna började, och i den vita regimens slutskede omfattade verksamheten fyra radiokanaler och två TV-kanaler. Voice of Zimbabwe hade däremot enbart sänt program från grannländer under frihetskampen. Zimbabwe Broadcasting Corporations yttre uppbyggnad baserar sig därför långt på de verksamhetsformer som existerade i landet före självständigheten.

Zimbabwe Broadcasting Corporation är underställt Informationsministeriet och således indirekt också republikens president samt parlamentet (Kangai - Ndhlova 1986: 240). Bolaget ägs och kontrolleras av staten, men det förväntas själv finansiera sin verksamhet. Största delen av inkomsterna samlas genom försäljning av reklamer och programtid. (Gumbo 1990: 8-9)

Radions kanalindelning härstammar från den rhodesiska tiden. Radio 1 fortsätter den så kallade "Radio General Services" verksamhet med aktualitetsprogram på engelska. Den forna "African Service" har döpts till Radio 2 och fortsätter sända musik, underhållning och information på de olika afrikanska språken åt den svarta befolkningen. Radio 3 fortsätter ungdomskanalen "Radio Jacarandas" verksamhet med lättare popprogram på engelska. Kanalens största publik är den urbana ungdomen. Radio 4 bjuder på undervisningsprogram åt den svarta landsortsbefolkningen. (Kangai - Ndhlova 1986: 245-246)

Kanalernas starka profilering kommer också fram i musikpolitiken. Radio 1 sänder mest äldre västerländsk pop och klassisk musik. Undervisningskanalen Radio 4 sänder i sin tur huvudsakligen lokal traditionell musik och pop. Största delen av radions musikutbud koncentreras till kanaler 2 och 3 . Radio 2 bjuder på mycket zimbabwisk och afrikansk samt internationell pop. Radio 3:s utbud består huvudsakligen av västerländsk, främst brittisk och amerikansk pop.

De två musikkanalernas profilering förstärks av kvotbestämmelser som radions ledning har utfärdat för att trygga utbudets geografiska bredd. Enligt priniciperna måste Radio 2:s musik vara till två tredjedelar av zimbabwiskt ursprung, och Radio 3:s utbud måste till en tredjedel vara afrikansk musik. 
Ur musikindustrins synvinkel är Radio 2 och Radio 3 de centrala medierna på grund av musikens framträdande roll i utbudet och kanalernas stora lyssnarsiffror. Enligt Zimbabwe Music Coprorations undersökning av skivkonsumenternas köpvanor hade $57,5 \%$ av kunderna hört just i radio om musiken som de införskaffade. Det nästviktigaste mediet var tidskrifterna, som var informationskälla för $12,4 \%$ av köparna. Televisionens andel var endast 7,4 \%. (Record Buyer Survey)

Radions stora roll återspeglas $i$ det att skivbolagen och återförsäljarna köper mycket programtid från radiokanalerna. Med hjälp av de här sponsorprogrammen vill bolagen försäkra sig om att publiken hör de produkter som musikindustrin vill sälja. I allmänhet samarbetar skivbolagen med något annat företag (t.ex. skivåter-försäljare eller klädaffär) och nöjer sig själv med att bestämma vilken musik som spelas.

Musikradions betydelse kommer också fram i det att skivbolagen tvingas beakta ZBC:s censurbestämmelser då de producerar sina skivor. Ett spelförbud leder i regel till att det blir så gott som omöjligt att marknadsföra skivan. Tidigare gällde censuren ofta politiskt känsliga ämnen, men numera är det huvudsakligen skivor med sexuella anspelningar som förbjuds.

Televisionens anspråkslösa betydelse för musikindustrin kan förklaras med mediets elitistiska karaktär i Zimbabwe. De båda TVkanalerna har var sitt program för musikvideor, men de når endast en liten skara lyssnare. Radions mellanvågssändningar täcker nämligen hela landet och FM-sändningarna så gott som hela landet. Televisionen däremot nådde ännu år 1987 bara $45 \%$ av Zimbabwe, och trots utvidgningar är nätet ännu bristfälligt (Rönning 1989: 12).

En viktig aspekt är också TV-mottagarnas antal i Zimbabwe. Enligt UNESCO:s World Communication Report (s. 426) beräknades TV-apparaternas antal år 1986 uppgå till 130.000, det vill säga 14 mottagare per tusen invånare. Siffrorna har knappast ökat märkbart under de senaste åren. Apparaternas priser är helt enkelt för höga för de flesta zimbabwierna.

Likaså kan pressens ringa betydelse för musikindustrin åtminstone delvis förklaras med en bristande spridning. Morgontidningarna noterar sällan händelser i musiklivet som helt lämnas åt de ungdomligare tidskrifterna. De månatliga utgåvorna Parade, Prize Beat och Horizon ägnar 3-6 sidor per nummer åt skivrecensioner, intervjuer och artiklar om aktuella händelser i branschen. De zimbabwiska tid- 
skrifterna har dock i allmänhet upplagor på endast 7.000-20.000 exemplar (Audio Visual Zimbabwe 1990-1991: 86-88), vilket innebär att till och med en större artikels direkta effekt kan antas vara förhållandevis liten.

\section{Upphovsrätt}

Zimbabwe har ratificerat den så kallade Bern-konventionen som garanterar både internationella och lokala kompositörers samt textförfattares rättigheter. I Zimbabwe övervakas upphovsmännens och förläggarnas rättigheter av Zimbabwe Music Rights Association (ZIMRA), som grundades år 1981 av den engelska organisationen Performing Right Society (PRS). (Atkinson 1991)

Redan på 1950-talet hade Performing Right Society en agentur i Zimbabwe, men då handelskontakterna mellan Storbritannien och Rhodesia bröts under UDI-perioden överförde PRS de rhodesiska rättigheterna till den sydafrikanska copyrightorganisationen SAMRO. Den zimbabwiska populärmusikens uppsving under frihetskampen fick PRS att grunda en lokal förening efter att landet hade blivit självständigt. Zimbabwe undertecknade också 1980 den s.k. Bernkonventionen om internationella rättigheter. Till en början hade Zimbabwe Music Rights Association endast 15 medlemmar, men numera har drygt 300 kompositörer skrivit in sig i organisationen. (ibid.)

Zimbabwe Music Rights Association och Performing Right Society har ett ömsesidigt kontrakt som innebär att ZIMRA övervakar de internationella upphovsmännens rätt i Zimbabwe och PRS övervakar de zimbabwiska rättigheterna i övriga världen. Enligt ZIMRA:s beräkning består till exempel Zimbabwe Broadcasting Corporations musikutbud till $50 \%$ av internationellt material och därför betalar föreningen hälften av inkomsterna från radion åt PRS för vidareförmedling. (ibid.)

Den zimbabwiska copyrightlagen baserar sig på Storbritanniens lagstiftning från 1956 och innefattar endast upphovsmännens rättigheter. Det här innebär att alla de inrättningar som spelar musik för en allmän publik är skyldiga att erlägga en ersättning som betalas åt kompositörerna, textförfattarna och förläggarna. Lagen förnyas dock som bäst och det har föreslagits att ett skydd för artister skulle införas. I den nya lagen kommer antagligen också den traditionella musiken och kulturen att beaktas. (Atkinson 1991) 
Trots att det juridiska skyddet har varit $\mathrm{i}$ kraft $\mathrm{i}$ över trettio år har Zimbabwe Music Rights Association fortfarande problem med övervakningen av rättigheterna. År 1982 hamnade ZIMRA i en dispyt med Zimbabwe Broadcasting Coproration som ifrågasatte föreningens rätt att samla ersättningar. Tvisten löstes slutligen 1989 med ett domstolsbeslut som gav ZIMRA rätt till 2,25 \% av rundradions reklamintäkter i ersättning för den musik som spelas i programmen. (Atkinson 1991)

Det är skäl att lägga märke till att det inte spelar någon roll hurudan musik radion spelar. Alla skivor prissätts lika och t.ex. den spelade musikens ursprungsland inverkar inte på ersättningarnas storlek.

I praktiken finns det alltjämt haltande punkter i det upphovsrättsliga systemet. Enligt Zimbabwe Music Rights Associations direktör Gillian Atkinson betalar föreningen ut ersättningar för radiospelning på basen av Zimbabwe Broadcasting Corporations spellistor. Detta torde dock vara så gott som omöjligt då föreningen till exempel ännu i augusti 1991 inte hade fått mera än en bråkdel av Radio 3:s spellistor för augusti 1990 .

\section{Strukturens återspeglingar i musikutbudet}

Den zimbabwiska fonogramindustrins genomgående drag är vinylskivans starka ställning fram till slutet av 1980-talet. Detta har lett till en låg piratism, som inte bara har varit en förutsättning för hela industrins verksamhet, utan också en faktor som har satt sin prägel på verksamhetens olika former och utbudets art.

Den låga piratismen har möjliggjort omfattande licenskontrakt med utländska bolag, som stöder den zimbabwiska industrin med hjälp av t.ex. råvaror och färdiga matriser till det licenserade materialet. Stödet har lett till att det är så mycket billigare att ge ut utländska skivor än att producera inhemska, att över $90 \%$ av LPskivorna och kassetterna består av utländsk musik. Samtidigt har de dyrare inhemska produktionerna blivit allt mera likriktade eftersom man endast vågar satsa på populära artister.

Kassetternas genombrott kan innebära en omvälvning i industrin. I bästa fall sker förändringarna enligt Petersons och Bergers klassiska modell (se Peterson-Berger 1975) så att den nya teknologin och de nya produktionsbolagen utvecklas hand $\mathrm{i}$ hand med ett mångsidigare 
musikutbud. Tillsvidare har dock de få bolag och artister som brutit industrins maktkoncentration lyckats enbart med hjälp av högst etablerade artister. I värsta fall leder kassetternas popularitet till en okontrollerad piratism som dödar hela den lagliga musikindustrin i landet.

Musikindustrins andra centrala filter - det zimbabwiska rundradiobolaget - är starkt tudelat vad musikkanalerna beträffar. Radio 2 har blivit den inhemska musikens viktigaste medium och Radio 3 sänder så gott som uteslutande utländsk musik. I praktiken har andelen av internationell musik blivit rätt stor, och framför allt i Radio 3 är kvotbestämmelserna, som borde skydda den inhemska musiken, betydelselösa. Enligt radiobolagets ledning borde en tredjedel av musiken vara av inhemskt ursprung, men i praktiken härstammar bara 7 \% från Zimbabwe.

En analys av både fonogramindustrins och radiokanalernas utbud visar tydligt hur den internationella musiken följer den västerländska underhållningsindustrins trender. Inflytandet kommer fram i såväl musikstil och språk, som geografiskt ursprung. Fast någon av variablerna inte direkt skulle överensstämma med principen så tycks det krävas att åtminstone de två andra följer regeln för att musikstycket skulle slå igenom. En kombination av alltför etniskt influerad musik, framförd på ett lokalt språk från ett geografiskt randområde har få chanser att klara sig.

Även om den internationella underhållningsindustrins produkter har en så framträdande roll i den zimbabwiska musikindustrins utbud, så skall man inte dra några förhastade slutsatser om publiken som "ett viljelöst offer för västerländsk mediaimperialism".

I fonogramindustrin är den importerade musikens andel stor, men ändå är det de zimbabwiska gruppernas musik som ger bolagen den största vinsten. Likaså är Radio 2, med sin inhemska programprofil, den absolut populäraste radiokanalen. Radio 3:s internationella utbud är inte heller entydigt en följd av de utländska bolagens marknadsföring. I själva verket är det de zimbabwiska discjockeyerna som själv importerar de utländska skivorna från London.

De internationella trendernas inflytande på Zimbabwes musikkultur har inte heller varit särdeles omfattande (med undantag av reggaen). En orsak till detta är förmodligen den skriande bristen på instrument och ny utrustning. Man kan också se publikens konservativa inställning som en hämmande delfaktor.

Zimbabwes traditionella musik kan kallas musikkulturens stora 
förlorare i kampen om en plats i mediafältet. Skivbolagen ger praktiskt taget inte alls ut traditionell musik och $\mathrm{i}$ radion hörs den endast i några av Radio 2:s specialprogram.

Den zimbabwiska musiken förändras dock hela tiden och numera har man också börjat elektrifiera traditionella instrument. Framtiden må visa hur experimenten fungerar i det föränderliga mediefältet.

\section{Källor}

Audio Visual Zimbabwe 1990-1991. A multimedia production directory (1990). Harare: Z Promotions.

Brusila, Johannes (1992), Filtreringen av nationella och internationella produkter i Zimbabwes musikindustri - en analys av grindvakternas funktioner $\mathrm{i}$ fonogramindustrin och rundradioverksamheten. Pro gradu -avhandling. Musikvetenskapliga institutionen, Helsingfors universitet.

Gumbo, O.Z. (1990), Analysis of income and expenditure statement for year ended 30 June 1990. - Channels Vol. 2, September/October 1990. Zimbabwe Broadcasting Corporation House Journal, s. 7-9.

Hirsch, P.M. (1969), The Structure of the Popular Music Industry. The filtering process by which records are preselected for public consumption. Michigan: Ann Arbor.

Howard, Julian (1992), Viability of the Music Industry in Zimbabwe. ZIMIA - The Forming of a Music Industry Association in Zimbabwe. Helsinki: Mediafrica, s. 30-38.

Kangai, Tirivafi John - Ndhlovu, Charles (1986), Zimbabwe Broadcasting Corporation: Voice of Zimbabwe. - Making Broadcasting Useful: The African Experience, red. Wedell G. Manchester: Manchester University Press, s. 240-248.

Peterson, R.A. - Berger, D.G. (1975), Cycles in Symbol Production. The Case of Popular Music. - On Record. Rock, Pop, and the Written Word, red. Frith, S. - Goodwin, A. (1990) New York: Pantheon Books, s. 140-159.

Record Buyer Survey. Zimbabwe Broadcasting Corporations konsumentundersökning. Duplikat.

Roskilly, Stephen (1992), Music Recording Studios. - ZIMIA - The Forming of a Music Industry Association in Zimbabwe, s. 716. Helsinki: Mediafrica.

Rönning, Helge (1989), The Structure of the Media in Zimbabwe. A survey of developments and problems. U-landsseminariets 
skriftserie, $\mathrm{nr}$ 47. Senter for internasjonale utvecklingsstudier. Oslo: Universitetet i Oslo.

Sandberg, Svante - Edenborg, Torkel (red.) (1990), Zimbabwe. Mellan svart och vitt. Helsingborg: Carlssons och Föreningen Svensk Volontärsamverkan.

Wallis, Roger - Malm, Krister (1984), Big sounds from small peoples. The music industry in small countries. London: Constable.

ZIMIA - The Forming of a Music Industry Association in Zimbabwe (1992), Helsinki: Mediafrica.

Zindi, Fred (1985), Roots Rocking in Zimbabwe. Gweru: Mambo Press.

Intervjuer

Annandale, Bill (18.7.1991, Harare), Spinalong, verkställande direktör. Atkinson, Gillian (26.3.1991, Harare), Zimbabwe Music Rights Association, direktör.

Hagelthorne, Tony (14.3.1991, Harare), Zimbabwe Music Corporation, verkställande direktör.

Howard, Julian (12.3.1991, Harare), Gramma Records, verkställande direktör.

Ralph, Mike (26.3.1991, Harare), Record and Tape Promotions, verkställande direktör.

Roskilly, Stephen (17.7.1991, Harare), Shed Studios, verkställande direktör.

Smith, David (8.3.1991, Harare), Music Express, verkställande direktör.

Opublicerat material

Listor över de zimbabwiska skivbolagens utbud (s.k. Release Sheets) från juni-augusti 1990

Listor över ZBC:s program och musikutbud, samt inspelningar av radioprogram från juli-september 1990 